\title{
Adjuvantes e assistência de ar em pulverizador de barras sobre a deposição da calda e controle de Phakopsora pachyrhizi (Sydow \& Sydow)
}

\author{
Hélio Oliveira Aguiar Júnior ${ }^{1,2}$, Carlos Gilberto Raetanoํㅡ, Evandro Pereira Prado, Mário Henrique Ferreira do \\ Aamaral Dal Pogetto ${ }^{1}$, Rafael de Souza Christovam ${ }^{1}$, Marcelo Júnior Gimenes ${ }^{1}$
}

${ }^{1}$ Faculdade de Ciências Agronômicas/UNESP-Departamento de Produção Vegetal-Defesa Fitossanitária-Caixa Postal 237, 18610-307 Fone: (18) 9743-4057 Botucatu/SP. ${ }^{2}$ Bolsista CNPq, parte da dissertação de mestrado do primeiro autor.

Autor para correspondência: Hélio Oliveira Aguiar Júnior (jraguiar@ hotmail.com )

Data de chegada: 05/08/2010. Aceito para publicação em: 03/06/2011.

\section{RESUMO}

Aguiar Júnior, H.O.; Raetano, C.G.; Prado, E.P.; Dal Pogetto, M.H.F.A.; Christovam, R.S.; Júnior Gimenes, M. Adjuvantes e assistência de ar em pulverizador de barras sobre a deposição da calda e controle de Phakopsora pachyrhizi (Sydow \& Sydow). Summa Phytopathologica, v.37, n.3, p.103-109, 2011.

Com o intuito de melhorar a cobertura da pulverização e diminuir as perdas na produtividade da cultura da soja, o estudo objetivou avaliar o efeito da adição de adjuvantes à calda combinado ou não ao uso da assistência de ar sobre a deposição da pulverização, controle de Phakopsora pachyrhizi H. Sydow \& P. Sydow, perdas de produção (peso de 1000 grãos) e produtividade da cultura $\left(\mathrm{kg} \mathrm{ha}^{-1}\right)$. Dois experimentos a campo foram conduzidos na cultura da soja, variedade Conquista, safra agrícola 2008/09. Um deles no delineamento em blocos ao acaso com três doses de adjuvantes associados a um marcador cúprico combinadas a dois níveis de ar na barra de pulverização ( 0 e $29 \mathrm{~km} \mathrm{~h}^{-1}$ ), totalizando 6 tratamentos e 4 repetições. Outro experimento foi instalado no mesmo local do anterior. O delineamento experimental utilizado foi o de blocos ao acaso com 7 tratamentos: fungicida e dois adjuvantes associados ao fungicida, combinados a dois níveis de ar na barra de pulverização $\left(0\right.$ e $\left.29 \mathrm{~km} \mathrm{~h}^{-1}\right)$, mais testemunha, e 4 repetições. Após a pulverização do fungicida piraclostrobina + epoxiconazole com diferentes tecnologias, procedeu-se a avaliação da severidade da doença através da estimativa da área abaixo da curva de progresso da doença (AACPD) e da produtividade da cultura da soja. A assistência de ar na velocidade máxima gerada pelo ventilador $\left(29 \mathrm{~km} \mathrm{~h}^{-1}\right)$, combinada ao fungicida piraclostrobina + epoxiconazole mais o adjuvante organosiliconado Silwet L-77 contribuiu para melhor controle da ferrugem asiática, proporcionando incremento na produtividade e no peso de 1000 grãos.

Palavras-chave adicionais: Tecnologia de Aplicação, controle químico, ferrugem asiática da soja

\section{ABSTRACT}

Aguiar Júnior, H.O.; Raetano, C.G.; Prado, E.P.; Dal Pogetto, M.H.F.A.; Christovam, R.S.; Júnior Gimenes, M. Adjuvants and air assistance in sleeve boom sprayer on spray deposition and control of Phakopsora pachyrhizi (Sydow \& Sydow). Summa Phytopathologica, v.37, n.3, p.103$109,2011$.

To improve the spray coverage and reduce the productivity losses of soybean crop, this study aimed to evaluate the effect of adding adjuvants to the spray solution combined with or without air assistance on spray deposition, Phakopsora pachyrhizi H. Sydow \& P. Sydow control, production losses (weight of 1000 grains) and soybean crop productivity $\left(\mathrm{kg} \mathrm{ha}^{-1}\right)$. Two experiments were conducted in the field with soybean crop, Conquista variety (season 2008/09). One of them was conducted in randomized block design with three doses of adjuvants associated with one cupric tracer. These treatments were also combined at two levels of air assistance on spray boom $\left(0\right.$ and $\left.29 \mathrm{~km} \mathrm{~h}^{-1}\right)$, totaling 6 treatments and 4 replicates. Another experiment was carried out in the same place of the previous experiment in a randomized block design with 7 treatments: fungicide and two adjuvants in mixture with the fungicide, combined with two levels of air assistance on spray boom (0 to $29 \mathrm{~km} \mathrm{~h}$ $\left.{ }^{1}\right)$, plus control, and 4 replicates. After spraying of the fungicide pyraclostrobin + epoxiconazole using different technologies, the soybean rust severity was evaluated by estimating the area under the disease progress curve (AUDPC) and soybean crop yield. Air assistance in maximum speed generated by a fan $\left(29 \mathrm{~km} \mathrm{~h}^{-1}\right)$, combined with the organosilicone adjuvant Silwet L-77 plus fungicide pyraclostrobin + epoxiconazole, contributed to improve soybean rust control increasing the productivity and weight of 1000 grains.

Keywords: Application technology, chemical control, soybean Asian rust

A ferrugem asiática da soja [Glycine max (L.) Merrill] causada pelo fungo Phakopsora pachyrhizi H. Sydow \& P. Sydow, possui alto potencial de dano à cultura pois pode causar rápido amarelecimento e queda prematura de folhas, prejudicando a plena formação dos grãos. Desde o ano de 2001, a doença tem causado prejuízos significativos à cultura da soja em quase todas as regiões do Brasil (4). Lavouras livres de doença podem alcançar uma produtividade média de 55 sacas $\mathrm{ha}^{-1}$.
Porém, o custo de produção encontra-se por volta de 40,3 sacas ha ${ }^{-1}$, sendo recomendável o controle do agente causal da doença (1).

O controle da ferrugem da soja compreende diversas medidas conjuntas, porém o controle químico com fungicidas pode ser considerado, até o momento, o principal método de controle. No entanto, em muitas aplicações, atingir o alvo biológico de maneira direta torna-se difícil em função de sua localização. Nestas situações, 
uma das alternativas que evita o desperdício oriundo do aumento do volume de calda para que uma pequena parte possa atingir o alvo de forma direta e exercer o controle é o uso de produtos com capacidade de redistribuição (17). Outra opção para proporcionar características desejáveis no controle do patógeno é a adoção de novas tecnologias, como a assistência de ar junto à barra de pulverização $(5,14,16)$.

Estudos evidenciam que o uso da assistência de ar junto à barra de pulverização reduz a deriva com possibilidade do aumento da penetração das gotas no dossel da cultura, além de melhorar a distribuição da pulverização $(5,10,19,20)$.

$\mathrm{Na}$ definição de estratégias para o controle da ferrugem, quanto à tecnologia de aplicação, devem ser observados conceitos básicos de como os fungicidas sistêmicos movimentam nas plantas após a aplicação e absorção. No mercado atual, a maioria dos fungicidas para a ferrugem apresenta movimentação no sentido da base para o topo de cada folíolo ou folha, com mínima chance de movimentação no sentido contrário e sem a possibilidade de translocação de uma folha para outra (3).

Para maximização do efeito dos produtos fitossanitários deve também ser levada em consideração à utilização dos adjuvantes. Entretanto, isso deve ser visto com cautela, pois o aumento da concentração dos adjuvantes junto à calda pode reverter esta situação (18).

Devido à complexidade das interações entre diferentes tecnologias de aplicação (2), muitos questionamentos ainda devem ser esclarecidos quanto à determinação do volume de calda, velocidade de ar e estádio de desenvolvimento da cultura mais adequado a diferentes angulações dos bicos na barra em relação ao ar, altura de pulverização, velocidade de deslocamento e utilização de adjuvantes, entre outros, visando propiciar maior cobertura da pulverização e menores perdas. Sendo assim, o presente trabalho teve como objetivos avaliar diferentes técnicas de aplicação (com e sem assistência de ar) junto à barra de pulverização, em presença ou não de adjuvantes etoxilado, cujo ingrediente ativo denomina-se nonil fenol etoxilado, classificado como tensoativo emulsionante (Antideriva) e adjuvantes do grupo químico organosiliconado, com copolímero de poliéter e silicone como ingrediante ativo (Silwet L77) classificado como agente molhante, sobre a deposição da pulverização, bem como o efeito dessas tecnologias no controle da ferrugem asiática da soja em condições de campo.

\section{MATERIAL E MÉTODOS}

Dois experimentos foram conduzidos na safra agrícola 2008/09, em área experimental da fazenda de Ensino, Pesquisa e Produção (FEPP) da FCA/UNESP - Campus de Botucatu, Gleba Cascalheira $\left(22^{\circ} 48^{\prime} 59,7^{\prime \prime} \mathrm{S}\right.$ e $\left.48^{\circ} 25^{\prime} 38,2^{\prime \prime} \mathrm{W}\right)$ na cultura da soja, cultivar Conquista. A semeadura da soja foi realizada no dia 27/11/2008 com espaçamento de $0,45 \mathrm{~m}$ entre linhas, densidade de 18 sementes $\mathrm{m}^{-1}$, e conduzida em sistema de semeadura direta. A adubação foi feita no sulco de semeadura com $320 \mathrm{~kg} \mathrm{ha}^{-1}$ da formulação comercial de N-P-K (04 20 20).

\section{Experimento 1}

Para avaliação da deposição da pulverização, um experimento foi conduzido no delineamento experimental em blocos ao acaso com três suspensões aquosas contendo o marcador oxicloreto de cobre (Tabela 1) combinadas a dois níveis de assistência de ar na barra de pulverização $\left(0\right.$ e $\left.29 \mathrm{~km} \mathrm{~h}^{-1}\right)$, totalizando 6 tratamentos e 4 repetições, conforme descritos na Tabela 1 . As dimensões das parcelas foram 8,0 × 9,0 m (largura x comprimento).

Um fungicida cúprico à base de oxicloreto de cobre (Cobox $50 \%$ ) foi utilizado como marcador, na concentração de $250 \mathrm{~g} 100 \mathrm{~L}$ ', para mensurar os níveis de depósitos da pulverização realizada em 19/02/2009, aos 83 dias após a semeadura (DAS), com a cultura no estádio de desenvolvimento reprodutivo R1.

O pulverizador foi equipado com barra de pulverização de 18,5 $\mathrm{m}$ de comprimento e 37 pontas de pulverização de jato plano XR 8002 , à pressão de $400 \mathrm{kPa}$, conferindo um volume de $150 \mathrm{~L} \mathrm{ha}^{-1}$. A barra foi mantida sempre a $0,5 \mathrm{~m}$ de altura em relação às plantas de soja com velocidade de deslocamento do conjunto tratorpulverizador de $7,2 \mathrm{~km} \mathrm{~h}^{-1}$.

No momento da pulverização do marcador cúprico, as condições ambientais foram: temperatura de $28,0 \pm 2{ }^{\circ} \mathrm{C}$; umidade relativa do ar de $63 \pm 10 \%$ e velocidade do vento entre 3 a $7 \mathrm{~km} \mathrm{~h}^{-1}$ no sentido Oeste, no período de $09 \mathrm{~h} 00 \mathrm{~min}$. às $13 \mathrm{~h} 50 \mathrm{~min}$.

Para a quantificação dos depósitos da pulverização foram colocados em cada parcela alvos artificiais (papel filtro com dimensões de $3 \times 3 \mathrm{~cm}$ ) distribuídos em 10 plantas tomadas ao acaso. Em cada uma das 10 plantas amostradas foram fixados quatro coletores (papel filtro), um na superfície adaxial e outro na superfície abaxial do mesmo folíolo nas partes superior e inferior da mesma planta. Após a pulverização, os alvos artificiais (papel filtro) foram retirados dos folíolos e colocados em vidros (capacidade de $30 \mathrm{~mL}$ ) contendo $20 \mathrm{~mL}$ de solução extratora de ácido nítrico a $1 \mathrm{Mol} \mathrm{L}^{-1}$, após 15 minutos de agitação e 24 horas de descanso, foram levados ao espectrofotômetro de absorção atômica, modelo AA- 6300 Shimadzu para quantificação do íon cobre $(\mathrm{Cu})$, conforme método utilizado por Chaim et al. (8).

Os dados médios dos depósitos da pulverização contendo a

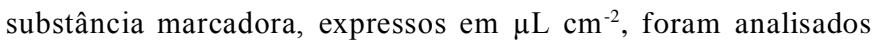
separadamente para cada posição dos alvos artificiais, e submetidos a analise de variância pelo teste $\mathrm{F}$ e as médias comparadas pelo teste de Tukey a $5 \%$ de probabilidade.

Tabela 1. Suspensões aquosas, doses e técnicas de pulverização.

\begin{tabular}{lcc}
\hline Suspensão aquosa & Dose & Técnica de pulverização \\
\hline oxicloreto de cobre & $375,0 \mathrm{~g} \mathrm{ha}^{-1}$ & Sem assistência de ar \\
oxicloreto de cobre + Silwet L-77 & $375,0 \mathrm{~g} \mathrm{ha}^{-1}+0,1\left(\% \mathrm{v} \mathrm{v}^{-1}\right)$ & \\
oxicloreto de cobre + Antideriva & $375,0 \mathrm{~g} \mathrm{ha}^{-1}+0,05(\% \mathrm{v} \mathrm{v})$ & Com assistência de ar * \\
\hline oxicloreto de cobre & $375,0 \mathrm{~g} \mathrm{ha}^{-1}$ & \\
oxicloreto de cobre + Silwet L-77 & $375,0 \mathrm{~g} \mathrm{ha}^{-1}+0,1\left(\% \mathrm{v} \mathrm{v}^{-1}\right)$ & \\
oxicloreto de cobre + Antideriva & $375,0 \mathrm{~g} \mathrm{ha}^{-1}+0,05(\% \mathrm{v} \mathrm{v})$ & \\
\hline
\end{tabular}

*Ventilador em velocidade máxima no equipamento Advance Vortex 2000 (29 km h $\left.{ }^{-1}\right)$. 


\section{Experimento 2}

Para avaliar o efeito da assistência de ar junto à barra de pulverização no controle de P. pachyrhizi, bem como sobre o peso de 1000 sementes e produtividade $\left(\mathrm{kg} \mathrm{ha}^{-1}\right)$, outro experimento foi instalado no mesmo local do experimento anterior. O delineamento experimental foi o de blocos ao acaso com 7 tratamentos: fungicida somente e fungicida adicionado aos adjuvantes etoxilado (Antideriva) e organosiliconado (Silwet L-77), combinados a dois níveis de assistência de ar na barra de pulverização $\left(0\right.$ e $\left.29 \mathrm{~km} \mathrm{~h}^{-1}\right)$, mais testemunha, onde não foi realizada nenhuma aplicação de fungicida (Tabela 2), em 4 repetições.

O tamanho das parcelas, equipamentos de pulverização e calibração foram os mesmos utilizados no experimento 1 .

Após a emergência da cultura da soja foram realizados levantamentos semanais para monitoramento da infestação natural da ferrugem asiática, causada pelo fungo P. pachyrhizi. Para avaliação da infestação da doença foram observados 15 folíolos de cada parcela da parte inferior das plantas e, quando confirmada a presença da doença, procedeu-se a primeira pulverização da mistura fungicida piraclostrobina + epoxiconazole.

Para o controle da ferrugem asiática na cultura da soja foram realizadas quatro pulverizações da mistura fungicida, uma no estádio de desenvolvimento vegetativo $\left(\mathrm{V}_{10}\right)$, aos 70 DAS, e as demais nos estádios de desenvolvimento reprodutivo $\left(\mathrm{R}_{1} ; \mathrm{R}_{3}\right.$ e $\left.\mathrm{R}_{5.2}\right)$, respectivamente correspondendo aos 84, 98 e 115 DAS. As condições meteorológicas durante as pulverizações são apresentadas na Tabela 3 .

A avaliação da severidade da ferrugem foi realizada a intervalos de aproximadamente sete dias, totalizando sete avaliações. A primeira avaliação da severidade foi feita aos 69 DAS. Foram atribuídas notas pela porcentagem de área visual lesionada pela doença em 15 folíolos retirados aleatoriamente da parte inferior das plantas, em cada parcela, utilizando a escala visual diagramática proposta por Godoy et al. (13).

Com os dados da severidade da doença, procedeu-se à construção da curva para determinação da área abaixo da curva de progresso da doença (AACPD), conforme metodologia proposta por Campbell \& Madden (7).

Para avaliação do efeito da assistência de ar, combinada ou não a diferentes caldas da pulverização no controle da ferrugem asiática sobre a produtividade da soja, fez-se a colheita com auxílio de uma colhedora de parcelas (Wintersteiger Nursery Master Elite A- 4910 Ried/Austria), estabelecendo-se como área útil as 3 linhas centrais da parcela, com 7 metros de comprimento cada. Após a colheita o valor de umidade dos grãos de soja foi ajustado a $13 \%$, fez-se a pesagem da massa de 1000 grãos e estabeleceu-se a produtividade média por tratamento $\left(\mathrm{kg} \mathrm{ha}^{-1}\right)$. O controle de insetos-praga da soja (lagartas desfolhadoras e percevejos) foram realizados sempre que estes atingiram o nível de dano econômico da cultura.

Os dados da massa de 1.000 grãos e produtividade foram submetidos à análise de variância pelo teste $\mathrm{F}$, e as médias dos tratamentos comparados, pelo teste de Tukey a $5 \%$ de probabilidade.

\section{RESULTADOS E DISCUSSÃO}

\section{Experimento 1}

Pela análise do volume médio dos depósitos em folíolos posicionados na parte superior das plantas e superfície adaxial não foram observadas diferenças significativas entre tratamentos, independente da técnica de pulverização. Já na parte superior da planta e superfície abaxial, o tratamento com a pulverização do marcador associado ao adjuvante organosiliconado (Silwet L-77) sem assistência de ar apresentou depósitos médios significativamente maiores em comparação ao tratamento sem assistência de ar e na ausência de um adjuvante (Tabela 4).

Nos alvos posicionados na parte superior da planta não foram observadas diferenças significativas para a variável técnica de aplicação (com e sem assistência ar). O fato de não ter sido detectada diferença significativa nos depósitos na parte superior das plantas de soja para

Tabela 2. Produtos fitossanitários, doses e técnica de pulverização.

\begin{tabular}{|c|c|c|}
\hline Produtos fitossanitários & Doses & Técnica de pulverização \\
\hline $\begin{array}{l}\text { piraclostrobina }+ \text { epoxiconazole } \\
\text { piraclostrobina }+ \text { epoxiconazole }+ \text { Silwet L-77 } \\
\text { piraclostrobina }+ \text { epoxiconazole }+ \text { Antideriva }\end{array}$ & $\begin{array}{c}25+66,5 \text { g i.a. ha } \\
25+66,5 \text { g i.a. ha }{ }^{-1}+0,1\left(\% v^{-1}\right) \\
25+66,5 \text { g i.a. } \text { ha }^{-1}+0,05\left(\% v^{-1}\right)\end{array}$ & Sem assistência de ar $\left(0 \mathrm{~km} \mathrm{~h}^{-1}\right)$ \\
\hline $\begin{array}{l}\text { piraclostrobina }+ \text { epoxiconazole } \\
\text { piraclostrobina }+ \text { epoxiconazole }+ \text { Silwet L-77 } \\
\text { piraclostrobina }+ \text { epoxiconazole }+ \text { Antideriva } \\
\text { Testemunha }\end{array}$ & $\begin{array}{c}25+66,5 \text { g i.a. ha } \\
25+66,5 \text { g i.a. } \text { ha }^{-1}+0,1\left(\% v^{-1}\right) \\
25+66,5 \text { g i.a. } \text { ha }^{-1}+0,05\left(\% v^{-1}\right) \\
\text { _ }\end{array}$ & Com assistência de ar $\left(29 \mathrm{~km} \mathrm{~h}^{-1}\right) *$ \\
\hline
\end{tabular}

*Ventilador operando em velocidade máxima no equipamento Advance Vortex 2000.

Tabela 3. Condições meteorológicas durante as pulverizações da mistura fungicida piraclostrobina + epoxiconazole para o controle da Phakopsora pachyrhizi. Botucatu, SP. 2009.

\begin{tabular}{|c|c|c|c|c|}
\hline \multirow{2}{*}{$\begin{array}{c}\text { Indicadores } \\
\text { meteorológicos }\end{array}$} & \multicolumn{4}{|c|}{ Dias após semeadura (Data) } \\
\hline & $70(06 / 02)$ & $84(20 / 02)$ & $98(06 / 03)$ & $115(23 / 03)$ \\
\hline Temperatura & $26,0 \pm 2{ }^{\circ} \mathrm{C}$ & $27,0 \pm 2{ }^{\circ} \mathrm{C}$ & $29,0 \pm 2^{\circ} \mathrm{C}$ & $26,0 \pm 2^{\circ} \mathrm{C}$ \\
\hline Umidade Relativa & $66 \pm 5 \%$ & $64 \pm 5 \%$ & $60 \pm 5 \%$ & $69 \pm 5 \%$ \\
\hline Velocidade do Vento & $\begin{array}{l}2 \text { a } 5 \mathrm{~km} \mathrm{~h}^{-1} \\
(8 \mathrm{~h} 00 \mathrm{~min}-11 \mathrm{~h} 00 \mathrm{~min})\end{array}$ & $\begin{array}{l}3 \text { a } 7 \mathrm{~km} \mathrm{~h}^{-1} \\
(8 \mathrm{~h} 10 \mathrm{~min}-10 \mathrm{~h} 30 \mathrm{~min})\end{array}$ & $\begin{array}{l}2 \text { a } 5 \mathrm{~km} \mathrm{~h}^{-1} \\
(9 \mathrm{~h} 40 \mathrm{~min}-10 \mathrm{~h} 15 \mathrm{~min})\end{array}$ & $\begin{array}{l}3 \text { a } 8 \mathrm{~km} \mathrm{~h}^{-1} \\
(8 \mathrm{~h} 00 \mathrm{~min}-10 \mathrm{~h} 45 \mathrm{~min})\end{array}$ \\
\hline
\end{tabular}


Tabela 4. Depósitos médios $\left(\mu \mathrm{L} . \mathrm{cm}^{-2}\right)$ de um marcador cúprico associado ou não a adjuvantes, em alvos artificiais (papel filtro) nas superfícies adaxial e abaxial dos folíolos da parte superior das plantas de soja, após pulverização com diferentes técnicas. Botucatu-SP, safra 2008/2009.

\begin{tabular}{|c|c|c|c|c|}
\hline \multirow{3}{*}{ Tratamento } & \multicolumn{2}{|c|}{ Adaxial } & \multicolumn{2}{|c|}{ Abaxial } \\
\hline & \multicolumn{4}{|c|}{ Assistência de ar } \\
\hline & Se m & Com & Se m & Com \\
\hline Silwet L -77 & $1,34 \mathrm{aA}$ & $1,25 \mathrm{aA}$ & $0,82 \mathrm{bA}$ & $0,71 \mathrm{aA}$ \\
\hline Antideriva & $1,52 \mathrm{aA}$ & $1,21 \mathrm{aA}$ & $0,52 \mathrm{abA}$ & $0,65 \mathrm{aA}$ \\
\hline Água & $1,25 \mathrm{aA}$ & $1,02 \mathrm{aA}$ & $0,48 \mathrm{aA}$ & $0,58 \mathrm{aA}$ \\
\hline $\mathrm{CV}(\%)$ & \multicolumn{2}{|c|}{21,11} & \multicolumn{2}{|c|}{27,54} \\
\hline DMS (Calda) & \multicolumn{2}{|c|}{0,48} & \multicolumn{2}{|c|}{0,31} \\
\hline DMS(Equipament & \multicolumn{2}{|c|}{0,39} & \multicolumn{2}{|c|}{0,26} \\
\hline
\end{tabular}

Médias seguidas de uma mesma letra minúscula/maiúscula em uma mesma coluna/linha, não diferem entre si pelo teste de Tukey a 5\% de probabilidade.

a variável técnica de aplicação revela que a assistência de ar, combinada à adição ou não de um adjuvante, não foi suficiente para melhorar a deposição da pulverização em relação à aplicação sem o uso da assistência de ar na parte superior das plantas.

Raetano \& Bauer (15), estudando diferentes velocidades da assistência de ar junto à barra de pulverização, também concluíram que a utilização da assistência de ar, operando a plena capacidade de rotação do ventilador, não resultou em significativo aumento nos níveis de depósitos nos folíolos posicionados na parte superior da cultura da soja, provavelmente devido à interceptação na trajetória das gotas pelos folíolos da parte superior da planta.

Pela análise do volume médio dos depósitos da pulverização em folíolos posicionados na parte inferior das plantas e superfície adaxial não foram observadas diferenças significativas nos tratamentos com assistência de ar, para a variável calda de pulverização (presença ou não de um adjuvante). Entre os tratamentos sem ar junto à barra aquele contendo o adjuvante organosiliconado (Silwet L-77) apresentou o maior nível de depósitos, diferindo significativamente do tratamento contendo o adjuvante etoxilado Antideriva (Tabela 5). Observando-se a variável técnica de pulverização, os tratamentos água e Antideriva apresentaram depósitos médios significativamente maiores em

Tabela 5. Depósitos médios $\left(\mu \mathrm{L} . \mathrm{cm}^{-2}\right)$ da pulverização de um marcador cúprico, associado ou não a adjuvantes, em alvos artificiais (papel filtro) nas superfícies adaxial e abaxial dos folíolos da parte inferior da plantas de soja, após pulverização com diferentes técnicas. BotucatuSP, safra 2008/2009.

\begin{tabular}{lcccc}
\hline \multirow{2}{*}{ Tratamento } & \multicolumn{2}{c}{ Adaxial } & \multicolumn{2}{c}{ Abaxial } \\
\cline { 2 - 5 } & \multicolumn{4}{c}{ Assistência de ar } \\
\cline { 2 - 5 } & S e m & C m & S m & Co m \\
\hline Silwet-77 & $0,61 \mathrm{bA}$ & $0,60 \mathrm{aA}$ & $0,54 \mathrm{aA}$ & $0,55 \mathrm{aA}$ \\
Antideriva & $0,51 \mathrm{aA}$ & $0,61 \mathrm{aB}$ & $0,41 \mathrm{aA}$ & $0,46 \mathrm{aA}$ \\
Água & $0,54 \mathrm{abA}$ & $0,65 \mathrm{aB}$ & $0,40 \mathrm{aA}$ & $0,38 \mathrm{aA}$ \\
\hline CV(\%) & & 7,67 & & 20,08 \\
DMS (Calda) & 0,08 & & 0,16 \\
DMS(Equipamento) & 0,07 & & 0,13 \\
\hline
\end{tabular}

Médias seguidas de uma mesma letra minúscula/maiúscula em uma mesma coluna/linha, não diferem entre si pelo teste de Tukey a 5\% de probabilidade. comparação aos mesmos tratamentos na ausência da assistência de ar (Tabela 5). Na parte inferior das plantas e superfície abaxial, os depósitos da pulverização não diferiram significativamente, independente da técnica de aplicação utilizada (com ou sem ar) e adição ou não de adjuvante à calda de pulverização.

Pode-se verificar também que, a calda contendo o adjuvante Silwet L-77 na presença ou não do ar, independente da posição (superior/ inferior) da planta, apresentou valores absolutos de depósitos maiores principalmente na superfície abaxial dos folíolos, em relação aos demais tratamentos. De acordo com Costa et al. (11), adjuvantes surfatantes interagem de diferentes maneiras com a solução onde foram adicionados, podendo promover melhorias na penetração, espalhamento e aderência das gotas ao alvo, conseqüentemente, maiores depósitos. Ressalta-se que os surfatantes têm em sua composição ingredientes redutores de tensão superficial, o que pode levar à diminuição do tamanho das gotas, favorecendo a cobertuda dos alvos (6). Ainda segundo esses autores, os surfatantes modificam a orientação das moléculas na interface líquido/superfície melhorando a dinâmica da gota sobre o alvo.

\section{Experimento 2}

$\mathrm{O}$ efeito do uso de surfatantes e de diferentes velocidades da assistência de ar junto à barra de pulverização no controle de $P$. pachyrhizi, representado pela área abaixo da curva de progresso da doença (AACPD), encontra-se nas Tabelas 6, 7 e 8. Nas avaliações realizadas aos 69, 75 e 81 dias após a semeadura (DAS), antes e depois da primeira aplicação da calda fungicida, não foram observadas diferenças significativas entre os tratamentos, tanto para o fator técnica de pulverização quanto para o tipo de calda fungicida utilizada nesse estudo. $\mathrm{O}$ fato de não terem sido constatadas diferenças significativas, nesse período, provavelmente seja em virtude da doença ainda estar em sua fase inicial, pois a primeira pulverização foi realizada imediatamente à confirmação do primeiro sintoma da doença na área experimental (70 DAS).

Após duas aplicações da calda fungicida, aos 70 e 84 DAS, na avaliação realizada aos 88 DAS, os tratamentos sem adição da assistência de ar e o tratamento com adição do surfatante Silwet L-77 assistido por ar apresentaram menores níveis de severidade da doença, diferindo significativamente da testemunha. Não foram também observadas diferenças significativas entre os fatores técnica de aplicação e caldas fungicidas, aos 96 DAS, embora todos os tratamentos que receberam aplicação da mistura fungicida apresentaram valores médios de pústulas significativamente menores em relação aos obtidos na testemunha (Tabela 7).

$\mathrm{Na}$ avaliação aos 103 DAS, após três pulverizações da calda fungicida, os tratamentos com o adjuvante Silwet L-77, em presença ou não de ar, apresentaram os menores números de pústulas. Todos os tratamentos que receberam aplicação da calda fungicida apresentaram valores médios da AACPD significativamente menores em comparação à testemunha (Tabela 7).

Aos 109 DAS, o tratamento fungicida + Silwet L-77 com assistência de ar apresentou o menor valor médio da AACPD $(49,16)$, seguido pelos tratamentos fungicida + Silwet L-77 sem ar e apenas fungicida sem assistência de ar. Todos os tratamentos que receberam aplicação da calda fungicida apresentaram severidade da doença significativamente menor em comparação à testemunha. Para o fator técnica de pulverização não foi observado diferença entre tratamentos (Tabela 8).

O tratamento fungicida + Silwet L-77 com assistência de ar, aos 118 DAS, apresentou o menor valor médio da AACPD $(48,66)$, seguido pelos tratamentos fungicida + Silwet L-77 sem ar e somente fungicida 


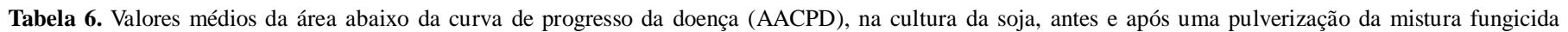
(piraclostrobina + epoxiconazole) associada ou não a adjuvantes em diferentes técnicas. Botucatu-SP, safra 2008/2009.

\begin{tabular}{|c|c|c|c|c|c|c|}
\hline \multirow{3}{*}{ Tratamentos } & \multicolumn{6}{|c|}{ Dias após a semeadura } \\
\hline & \multicolumn{2}{|c|}{69} & \multicolumn{2}{|c|}{75} & \multicolumn{2}{|c|}{81} \\
\hline & Sem Ar & Com Ar & Sem Ar & Com Ar & Sem Ar & Com Ar \\
\hline Fungicida + Silwet L-77 & $0,04 \mathrm{aA}$ & $0,03 \mathrm{aA}$ & $0,60 \mathrm{aA}$ & 1,16 aA & 8,02 aA & 5,19 aA \\
\hline Fungicida + Antideriva & $0,01 \mathrm{aA}$ & $0,10 \mathrm{aA}$ & $0,76 \mathrm{aA}$ & $1,28 \mathrm{aA}$ & 6,62 aA & $16,44 \mathrm{aA}$ \\
\hline Fungicida & $0,02 \mathrm{aA}$ & $0,00 \mathrm{aA}$ & $0,98 \mathrm{aA}$ & $0,61 \mathrm{aA}$ & 3,69 aA & 7,68 aA \\
\hline Testemunha & \multicolumn{2}{|c|}{0,09 a } & \multicolumn{2}{|c|}{$1,16 \mathrm{a}$} & \multicolumn{2}{|c|}{$11,20 \mathrm{a}$} \\
\hline C.V. $(\%)$ & \multicolumn{2}{|c|}{144,31} & \multicolumn{2}{|c|}{87,61} & \multicolumn{2}{|c|}{78,95} \\
\hline DMS (Calda) & \multicolumn{2}{|c|}{0,13} & \multicolumn{2}{|c|}{1,74} & \multicolumn{2}{|c|}{13,48} \\
\hline DMS (Equipamento) & \multicolumn{2}{|c|}{0,097} & \multicolumn{2}{|c|}{1,30} & \multicolumn{2}{|c|}{10,08} \\
\hline
\end{tabular}

Médias seguidas de uma mesma letra minúscula/maiúscula em uma mesma coluna/linha, não diferem entre si pelo teste de Tukey a 5\% de probabilidade.

Tabela 7. Valores médios da área abaixo da curva de progresso da doença (AACPD) na cultura da soja, após três pulverizações da mistura fungicida (piraclostrobina + epoxiconazole), associada ou não a um adjuvante, em diferentes técnicas. Botucatu-SP, safra 2008/2009.

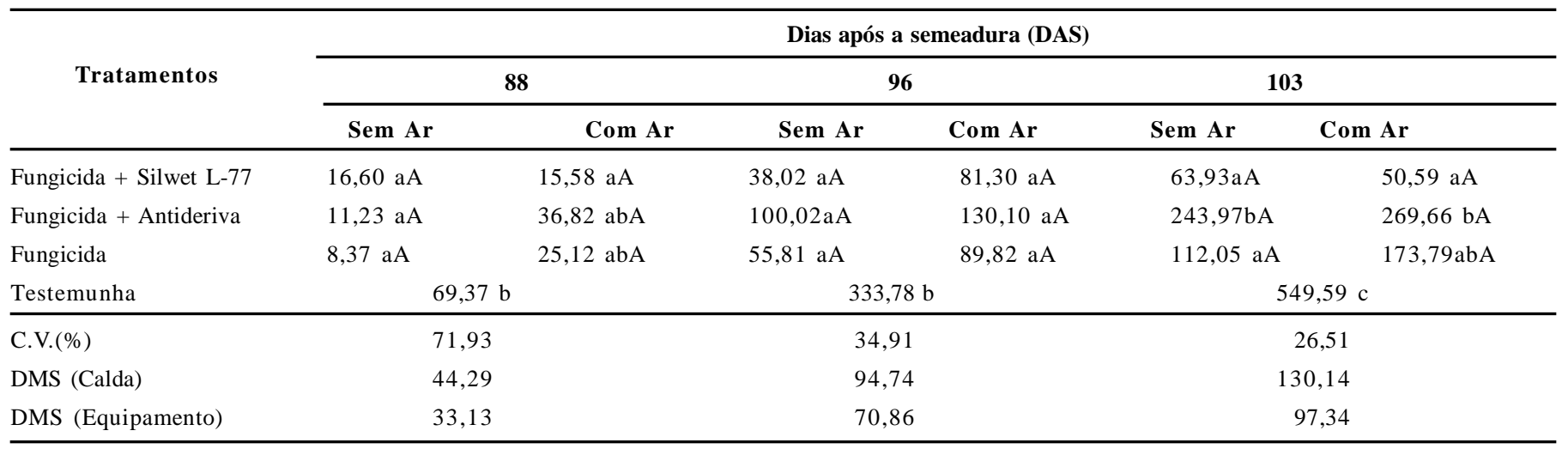

Médias seguidas de uma mesma letra minúscula/maiúscula em uma mesma coluna/linha, não diferem entre si pelo teste de Tukey a $5 \%$ de probabilidade.

com e sem assistência de ar, diferindo significativamente dos demais tratamentos. Todos os tratamentos que receberam aplicação da calda fungicida apresentaram diferença significativa em comparação à testemunha. Somente foi observada diferença significativa para o fator técnica de pulverização, aos 118 DAS, onde o tratamento sem adição de adjuvante e na ausência de ar mostrou-se melhor no controle da doença em relação ao mesmo tratamento com ar assistido.

$\mathrm{Na}$ avaliação do total acumulado da AACPD (Tabela 8), o tratamento fungicida + Silwet L-77 com assistência de ar, apresentou o menor valor médio $(202,09)$, seguido pelos tratamentos fungicida + Silwet L-77 sem ar e apenas fungicida e sem assistência de ar. Todos os tratamentos que receberam aplicação da calda fungicida diferiram significativamente em comparação à testemunha. Para o fator técnica de pulverização foi observada diferença significativa apenas entre os tratamentos sem adição de um adjuvante, onde o tratamento sem assistência de ar mostrou melhor controle da doença.

No geral, a combinação fungicida + Silwet L-77 apresentou a menor AACPD. Já a combinação fungicida + Antideriva apresentou as maiores AACPD em quase todas as avaliações. Todos os tratamentos que receberam aplicação da calda fungicida apresentaram diferença significativa em comparação à testemunha, evidenciando que o uso da mistura fungicida associada ou não a um adjuvante foi essencial para a redução da doença.

No entanto, quando o fungicida foi associado a um adjuvante essa combinação promoveu maior ou menor controle da doença. De acordo com Durigan (12), a melhoria na cobertura vegetal, bem como na penetração e absorção dos agroquímicos nas plantas, será obtida quanto mais semelhante forem às características físico-químicas da superfície vegetal e do adjuvante selecionado. Nesse aspecto, os organosiliconados como o Silwet L-77 são mais eficientes na redução da tensão superficial de soluções aquosas possibilitando maior contato da calda com a superfície vegetal.

A utilização de $100 \%$ da assistência de ar na ausência de adjuvante apresentou a tendência de promover menor controle da doença diferindo do mesmo tratamento com ausência do ar. Para os tratamentos com adição de adjuvante essa tecnologia não apresentou influência significativa sobre a severidade da doença.

A ocorrência de menores depósitos na parte inferior pode estar relacionada à interceptação das gotas pelas folhas das partes superior e média da planta, já relatado por Raetano \& Bauer (15) ao utilizar a assistência de ar na capacidade máxima de rotação do ventilador. A pulverização com o adjuvante organosiliconado, na ausência de ar, pode ter auxiliado na melhoria da cobertura foliar, pois o menor número das gotas foi suficiente para distribuir adequadamente a calda fungicida na superfície foliar.

Avaliando a produtividade da cultura observa-se que todos os tratamentos que receberam a aplicação da mistura fungicida diferiram significativamente quando comparados à testemunha (Tabela 9). Com destaque para o tratamento com assistência de ar $\left(29 \mathrm{~km} \mathrm{~h}^{-1}\right)$ associado ao adjuvante Silwet L-77 que diferiu significativamente dos demais 
Tabela 8. Valores médios da área abaixo da curva de progresso da doença (AACPD), na cultura da soja, antes e após 4 pulverizações da mistura fungicida piraclostrobina + epoxiconazole associada ou não a um adjuvante com diferentes técnicas. Botucatu-SP, safra 2008/2009.

\begin{tabular}{|c|c|c|c|c|c|c|}
\hline \multirow{3}{*}{ Tratamentos } & \multicolumn{6}{|c|}{ Dias após a semeadura } \\
\hline & \multicolumn{2}{|c|}{109} & \multicolumn{2}{|c|}{118} & \multicolumn{2}{|c|}{ Total } \\
\hline & Sem AR & Com Ar & Sem AR & Com Ar & Sem Ar & Com Ar \\
\hline Fungicida + Silwet L-77 & 85,44 aA & 49,16 aA & $100,27 \mathrm{aA}$ & 48,66 aA & $312,87 \mathrm{aA}$ & 202,09 aA \\
\hline Fungicida + Antideriva & $263,78 \mathrm{bA}$ & $318,50 \mathrm{bA}$ & $256,50 \mathrm{bA}$ & $320,81 \mathrm{bA}$ & $882,80 \mathrm{abA}$ & $1093,61 \mathrm{bA}$ \\
\hline Fungicida & 106,72 aA & $204,69 \mathrm{abA}$ & 103,75 aA & $278,57 \mathrm{bB}$ & $391,35 \mathrm{aA}$ & $780,27 \mathrm{bB}$ \\
\hline DMS (Calda) & \multicolumn{2}{|c|}{119,32} & \multicolumn{2}{|c|}{124,70} & \multicolumn{2}{|c|}{409,36} \\
\hline DMS (Equipamento) & \multicolumn{2}{|c|}{89,24} & \multicolumn{2}{|c|}{93,26} & \multicolumn{2}{|c|}{306,17} \\
\hline
\end{tabular}

Médias seguidas de uma mesma letra minúscula/maiúscula em uma mesma coluna/linha, não diferem entre si pelo teste de Tukey a 5\% de probabilidade.

Tabela 9. Efeito do uso de adjuvantes e assistência de ar no controle de Phakopsora pachyrhizi sobre a produtividade e peso de 1000 grãos na cultura da soja, var. Conquista, após 4 pulverizações da mistura fungicida piraclostrobina + epoxiconazole. Botucatu-SP, safra 2008/2009.

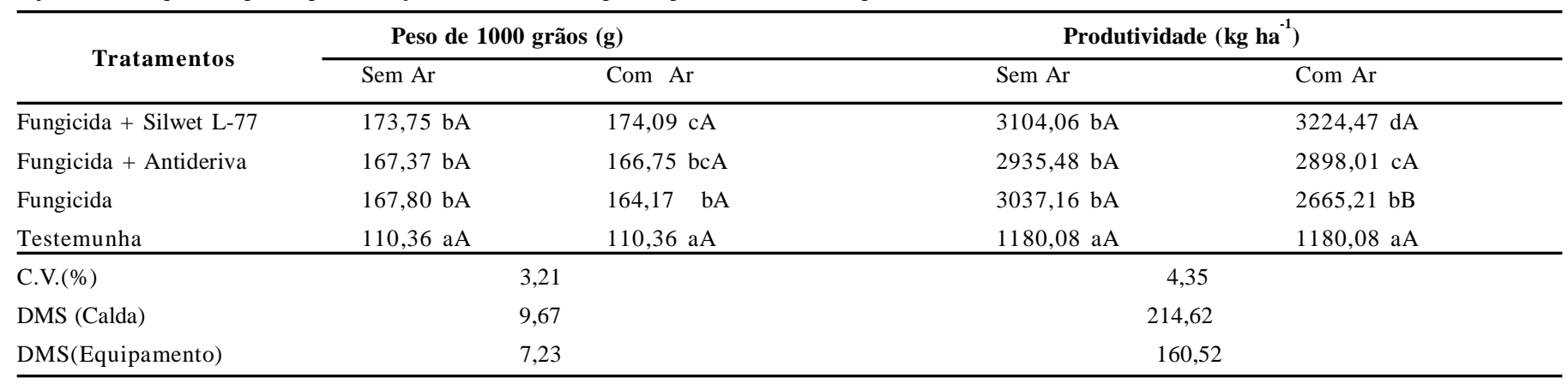

Médias seguidas de uma mesma letra minúscula/maiúscula em uma mesma coluna/linha, não diferem entre si pelo teste de Tukey a 5\% de probabilidade.

tratamentos assistidos por ar, apresentando a maior média de produtividade $\left(3.224 \mathrm{~kg} \mathrm{ha}^{-1}\right)$.

Para os tratamentos que receberam a calda fungicida na ausência da assistência de ar não foram observadas diferenças significativas, os quais diferiram apenas da testemunha. Ao observar o parâmetro técnica de aplicação, apenas no tratamento sem adição de um adjuvante foi notada diferença significativa, onde o tratamento sem ar apresentou maior produtividade quando comparado ao tratamento assistido por ar.

Em relação à massa de 1000 grãos, todos os tratamentos que receberam pulverização da calda fungicida diferiram significativamente da testemunha (Tabela 9). O tratamento com assistência de ar (29 km $\mathrm{h}^{-1}$ ) associado ao adjuvante Silwet L-77 apresentou o maior peso da massa de 1000 grãos.

Christovam (9), estudando o efeito de diferentes velocidades de ar e ângulos da barra pulverizadora no controle da ferrugem asiática da soja, variedade Conquista, encontrou resultados semelhantes de produtividade em relação aos obtidos nesse trabalho. O autor também constatou acréscimo de produtividade quando não foi utilizada a assistência de ar em comparação ao uso dessa tecnologia junto à barra de pulverização na velocidade máxima do ventilador $\left(29 \mathrm{~km} \mathrm{~h}^{-1}\right)$.

\section{CONCLUSÃO}

A assistência de ar combinada ao uso de adjuvantes junto à calda de pulverização não influenciou os valores dos depósitos médios $(\mu \mathrm{L}$ $\mathrm{cm}^{-2}$ ) da pulverização, peso de 1000 grãos e produtividade da soja variedade Conquista;

A assistência de ar na velocidade máxima gerada pelo ventilador $\left(29 \mathrm{~km} \mathrm{~h}^{-1}\right)$ na pulverização da mistura fungicida piraclostrobina + epoxiconazole mais o adjuvante Silwet L-77 contribuiu para melhor controle da ferrugem asiática, proporcionando incremento na produtividade.

\section{REFERÊNCIAS BIBLIOGRÁFICAS}

1. Alves, M.C.; Pozza, E.A.; Ferreira, J.B.; Araújo, D.V.; Costa, J.C.B.; Deuner, C.C.; Muniz, M.F.S.; Zambenedetti, E.B.; Machado, J.C. Intensidade da ferrugem asiática (Phakopsora pachyrhizi H. Sydow \& P. Sydow) da soja [Glycine max (L.) Merrill] nas cultivares Conquista, Savana e Suprema sob diferentes temperaturas e períodos de molhamento foliar. Summa Phytopathologica, Botucatu, v.33, n.3, p.239-244, 2007.

2. ANDEF - Associação Nacional de Defesa Vegetal. Manual de tecnologia de aplicação. Campinas: Línea Creativa, 2004. 50p.

3. Antuniassi, U.R. Tecnologia de aplicação para o controle da ferrugem da soja. In: Workshop Brasileiro sobre a Ferrugem Asiática, 1, 2005, Uberlândia. Coletânea... Uberlândia: EDUFU, 2005. p.193-219.

4. Azevedo, L.A.S. de; Juliatti, F.C.; Barreto, M. Resistência de genótipos de soja à Phakospsora pachyrhizi. Summa Phytopathologica, Botucatu, v.33, n.3, p.252-257, 2007.

5. Bauer, F.C.; Raetano, C.G. Assistência de ar e perdas na deposição de produtos fitossanitários em pulverizações na cultura da soja. Scientia Agricola, Piracicaba, v.57, n.2, p. 271-6, 2000. 
6. Butler-Ellis, M.C.; Tuck, C.R.; Miller, P.C.H. How surface tension and surfactant solutions influences the characteristics of sprays produced by hydraulic nozzles used for pesticides application. Colloids Surfaces A: Physicochemical and Engineering Aspects, v. 190, n. 3, p. 267-276, 2001.

7. Campbell, C.L.; Madden, L.V. Introduction to plant disease epidemiology. New York: John Wiley e Sons, 1990. 532p.

8. Chaim, A.; Valarini, P.J.; Oliveira, D.A.; Morsoleto, R.V.; Pio, L.C. Avaliação de perdas de pulverização em cultura de feijão e tomate. Jaguariúna: Embrapa Meio Ambiente, Jaguariúna, 1999. 29p. (Boletim de Pesquisa).

9. Christovam, R.S. Assistência de ar e aplicação em volume baixo no controle da ferrugem asiática da soja. Botucatu, 2008. 68f. Dissertação (Mestrado em agronomia/Proteção de Plantas) - Faculdade de Ciências Agronômicas, Universidade estadual Paulista.

10. Cooke, B.K.; Hislop, E.C.; Herrington, P.J.; Western, N.M.; Hunpherson-Jones, F. Air-assisted spraying of arable crops, in relation to deposition, drift and pesticides performance. Crop Protection, London, v.9, n.4, p.697, 1990.

11. Costa, N.V.; Martins, D.; Rodella, R.A.; Costa, L.D.N.C. pH foliar e deposição de gotas de pulverização em plantas daninhas aquáticas: Brachiaria mutica, Brachiaria subquadripara e Panicum repens. Planta Daninha, Viçosa, v. 23, n.2, p. 295-304, 2005

12. Durigan, J.C. Efeitos de adjuvantes na aplicação e eficácia dos herbicidas. Jaboticabal: FUNEP, 1993. 42p.

13. Godoy, C.V.; Koga, L.J.; Canteri, M.G. Diagrammatic scale for assessment of soybean rust severity. Fitopatologia Brasileira, Brasília, v.31, n.1, p.63-68, 2006

14. Jorgensen, L.; Witt, K.L. Spraying and the impact on the environment: Spraying technique in relation to approval and use of pesticides in Northern Europe. In: Hardi International. Hardi international application technology course 2000 . Taastrup, 2000. v. 1, chap. 2, p. 4-16.

15. Raetano, C.G.; Bauer, F.C. Efeito da velocidade do ar em barra de pulverização na deposição de produtos fitossanitários em feijoeiro. Bragantia, Campinas, v.62, n.2, p.329-334, 2003.

16. Raetano, C. G.; Merlin, A. Avanços tecnológicos no controle da ferrugem da soja. In: Zambolim, L. Ferrugem asiática da soja. Viçosa: UFV, 2006. p.115-138.

17. Ramos, H.H.; Matuo, T.; Bernardi, J.A. Características da pulverização produzida por bicos Yamaho da série "D". In: Congresso Brasileiro de Engenharia Agrícola, 30., 2001, Foz do Iguaçu. Anais... Foz do Iguaçu: 2001. 1 CD ROM.

18. Reeves, B.G. The rationale of adjuvant use with agrichemicals. In: FOY, C. L. (ed.) Adjuvants for agrichemicals. CRC Press, Boca Raton, 1992. p. 487-8.

19. Taylor, W.A.; Andersen, P.G.; Cooper, S. The use of air assistance in a field crop sprayer to reduce drift and modify drop trajectories. In: Brighton Crop Protection Conferenceweeds, 3., 1989, Brighton. Proceedings... Farnham: British Crop Protection Council, 1989. p. 631.

20. Taylor, W.A.; Andersen, P.G. Enhancing conventional hydraulic nozzle use with the Twin Spray System. British Crop Protection Council Monograph, v.46, p. 125-136, 1991. 